\title{
Next Generation Extractants for Cesium Separation from High-Level Waste: From Fundamental Concepts to Site Implementation
}

\author{
Bruce A. Moyer," Peter V. Bonnesen, Jeffrey C. Bryan, Nancy L. Engle, Tatiana G. Levitskaia, \\ and Richard A. Sachleben \\ Chemical and Analytical Sciences Division, Oak Ridge National Laboratory, \\ P.O. Box 2008, Oak Ridge, TN 37830-6119 \\ Richard A. Bartsch and Vladimir S. Talanov \\ Department of Chemistry and Biochemistry \\ Texas Tech University \\ Lubbock, TX 79409-1061 \\ Harry W. Gibson and Jason W. Jones \\ Department of Chemistry \\ Virginia Polytechnic Institute \& State University \\ Blacksburg, VA 24061
}

FY 2001 Annual Report to be submitted to the Environmental Management Science Program and to be posted on the internet.

\section{CAUTION}

The submitted manuscript has been authored by a contractor of the U. S. Government under contract No. DE-AC05-00OR22725. Accordingly, the U.S. Government retains a non-exclusive, royalty-free license to publish or reproduce the published form of this contribution, or allow others to do so, for the U.S. Government purposes.

Research at ORNL and PNNL was sponsored by the Environmental Management Science Program of the Offices of Science and Environmental Management, U. S. Department of Energy, under a) contract no. DE-AC05-00OR22725 with Oak Ridge National Laboratory, managed and operated by UT-Battelle, LLC; and b) contract no. DE-AC06-76RLO 1830 with Pacific Northwest National Laboratory, operated by Battelle. Research at Texas Tech University was sponsored by the Division of Chemical Sciences, Geosciences, and Biosciences, Office of Basic Energy Sciences, U.S. Department of Energy, under contract DE-FG03-94ER14416 with Texas Tech University. The participation of J.W.J. and T.G.L. was made possible by an appointment to the Oak Ridge National Laboratory Postgraduate Program administered by the Oak Ridge Associated Universities. 


\section{Project 73803 FY 2001 Annual Report}

Next Generation Extractants for Cesium Separation from High-Level Waste: From

Fundamental Concepts to Site Implementation

Aug. 20, 2001

Lead Principal Investigator: Bruce A. Moyer, Oak Ridge National Laboratory, Bldg. 4500S, MS 6119, P.O. Box 2008, Oak Ridge, TN 37831-6119. Phone: 865-574-6718. Fax: 865-574-4939. E-mail: moyerba@ornl.gov

Collaborator: Prof. Harry W. Gibson, Dept. of Chemistry, Virginia Polytechnic Institute \& State University, Blacksburg, VA, 24061. Phone: 540-231-5902. Fax: 540-231-8517. E-mail: hgibson@chemserver.chem.vt.edu

Collaborator: Prof. Richard A. Bartsch, Dept. of Chemistry and Biochemistry, Texas Tech University, Lubbock, TX 79409-1061. Phone: 806-742-3069. Fax: 806-742-1289. E-mail: richard.bartsch@ttu.edu

Collaborator: Dr. Benjamin P. Hay, Pacific Northwest National Laboratory, 902 Battelle Boulevard, P.O. Box 999, MSIN: K1-83, Richland, WA 99352. Phone: 509-372-6239. Fax: 509-375-6631. E-mail: ben.hay@pnl.gov

Investigator: Peter V. Bonnesen, Oak Ridge National Laboratory, Bldg. 4500S, MS 6119, P.O. Box 2008, Oak Ridge, TN 37831-6119. Phone: 865-574-6715. Fax: 865-574-4939. E-mail: bonnesenpv@ornl.gov

Investigator: Jeffrey C. Bryan, Oak Ridge National Laboratory, Bldg. 4500S, MS 6119, P.O. Box 2008, Oak Ridge, TN 37831-6119. Phone: 865-574-5018. Fax: 865-574-4939. E-mail: bryanjc@ornl.gov

Visiting Scientist: Richard A. Sachleben, Oak Ridge National Laboratory, Bldg. 4500S, MS 6119, P.O. Box 2008, Oak Ridge, TN 37831-6119. Phone: 865-576-2048. Fax: 865-574-4939. E-mail: rick@csg.chem.ornl.gov

Number of graduate students: 1 (VPI)

Number of postdocs: 2 (1 at ORNL and 1 at TTU) 


\section{Research Objective}

This project seeks a fundamental understanding and major improvement in cesium separation from high-level waste by cesium-selective calixcrown extractants. Systems of particular interest involve novel solvent-extraction systems containing specific members of the calix[4]arene-crown-6 family, alcohol solvating agents, and alkylamines. Questions being addressed bear upon cesium binding strength, extraction selectivity, cesium stripping, and extractant solubility. Enhanced properties in this regard will specifically benefit applied projects funded by the USDOE Office of Environmental Management to clean up sites such as the Savannah River Site (SRS), Hanford, and the Idaho National Environmental and Engineering Laboratory. The most direct beneficiary will be the SRS Salt Processing Project, which has recently identified the Caustic-Side Solvent Extraction (CSSX) process employing a calixcrown as its preferred technology for cesium removal from SRS high-level tank waste.

Disposal of high-level waste is horrendously expensive, in large part because the actual radioactive matter in underground waste tanks at various USDOE sites has been diluted over 1000 -fold by ordinary inorganic chemicals. To vitrify the entire mass of the high-level waste would be prohibitively expensive. Accordingly, an urgent need has arisen for technologies to remove radionuclides such as ${ }^{137} \mathrm{Cs}$ from the high-level waste so that the bulk of it may be diverted to cheaper low-level waste forms and cheaper storage. To address this need in part, chemical research at Oak Ridge National Laboratory (ORNL) has focused on calixcrown extractants, molecules that combine a crown ether with a calixarene. This hybrid possesses a cavity that is highly complementary for the $\mathrm{Cs}^{+}$ion vs. the $\mathrm{Na}^{+}$ion, making it possible to cleanly separate cesium from wastes that contain 10,000- to 1,000,000-fold higher concentrations of sodium. Previous EMSP results in Project 55087 elucidated the underlying extraction equilibria in cesium nitrate extraction by the calixcrown used in the CSSX process, calix[4]arene-bis $(t$ octylbenzo-crown-6), designated here as BOBCalixC6 (see structure). This understanding led to key improvements in the development of the CSSX process under the EM Efficient Separations and Crosscutting Program, entailing a method to back-extract or "strip" cesium from the calixcrown subsequent to cesium extraction from waste. Having this stripping method allowed the cesium to be concentrated in a relatively pure aqueous stream and the extractant to be regenerated for recycle. Closing the cycle then made possible the design of a process flowsheet and successful demonstration through collaboration with Argonne National Laboratory and Savannah River Technology Center under funding from the USDOE Office of Project Completion and Tanks Focus Area.

Despite

these successes, the CSSX process represents young technology that can benefit substantially from further fundamental inquiry. First, reversibility of the process (stripping efficiency) still presents the greatest potential for

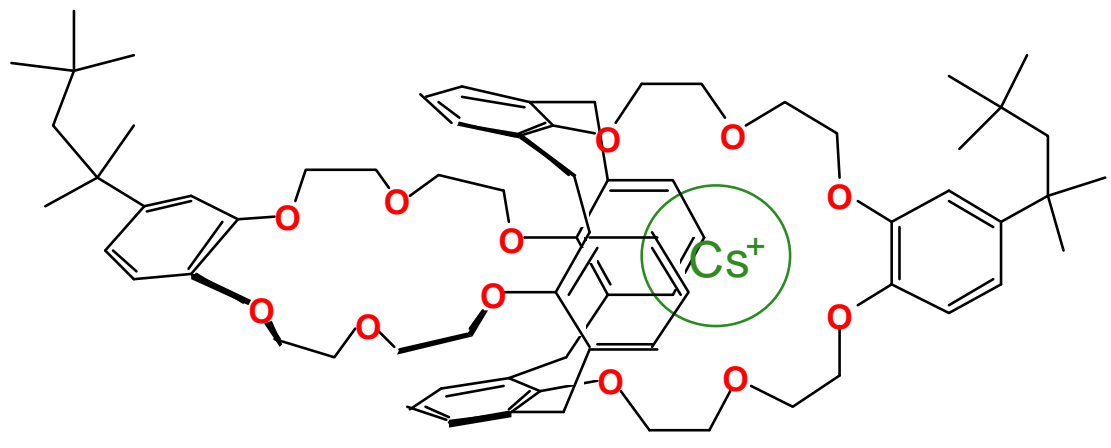

Calix[4]arene-bis( t-octylbenzo-crown-6) "BOBCalixC6"

(As complexed with $\mathrm{Cs}^{+}$ion) 
problems and the greatest potential for improvement. Second, although the calixcrown extractants for cesium are two orders of magnitude stronger than the next best simple crown ether, a minor fraction of the extractant capacity is utilized. Third, potassium competes significantly with cesium for the calixcrown binding site, an important issue in dealing with Hanford wastes having potassium concentrations as high as $1 \mathrm{M}$. Fourth, the calixcrown solubility needs to be improved. And finally, the mechanism of extraction must be understood in detail to provide the base of knowledge from which further development of the technology can be rationally made.

Toward addressing these needs, synthesis and characterization of new solvent components are being performed at ORNL and through collaboration with Texas Tech University (Prof. R. A. Bartsch). Extraction behavior is being surveyed to assess the effectiveness of candidate solvent systems, and systematic distribution measurements will be modeled toward a thermodynamic understanding of controlling equilibria. Complexation phenomena will be the focus of studies at Virginia Polytechnic Institute \& State University (Prof. H. W. Gibson). Structure-function relationships will be deduced through X-ray crystallography of candidate extractants at ORNL and collaboration with PNNL on molecular modeling (B. P. Hay). The overall objective is a significant advance in the predictability and efficiency of cesium extraction from high-level waste in support of potential implementation at USDOE sites.

\section{Research Progress and Implications}

This report summarizes work performed during the first 9 months of a three-year project. Significant progress in this time has been obtained on synthesis of new alkylated calixcrowns for enhanced solubility and extraction studies of new ionizable calixcrowns for improved extraction and stripping efficiency.

Toward improved calixcrown solubility, the immediate precursors for three analogs of calix[4]arene-bis-(tert-octylbenzo-crown-6) have been prepared. The analogs have various other alkyl chains substituted for the tert-octyl alkyl chain on the benzo-crown portion of the calixarene-crown-ether molecule. The choice of which alkyl groups to investigate was based upon a combination of ease of synthesis and the effect the alkyl group might have on the solubility of the calixarene-crown ether in hydrocarbon diluents. For example, one of the analogs will contain 2-ethylhexyl chains, which should improve solubility relative to the tertoctyl chains. The syntheses of these analogs (final products) should be complete by the end of FY 2001. A better understanding of the relationship between calixcrown solubility and alkyl substituent structure will be invaluable in design of more effective extractants and solvent systems.

A report of new ionizable calix[4]arene-biscrown- 6 compounds by $\mathrm{R}$. A. Bartsch and coworkers at Texas Tech University afforded an opportunity to examine whether a cation-exchange mechanism could provide a significant enhancement in extraction and stripping efficiency. Under funding by the USDOE Office of Basic Energy Sciences, Prof. Bartsch graciously provided a sample of one of the reported compounds for extraction tests (see figure at right). Extraction modeling revealed that the compound indeed behaves according to a cation-exchange mechanism but is still weakly capable of ionpair extraction. Although good extraction strength and selectivity were observed, the cation exchange was too strong

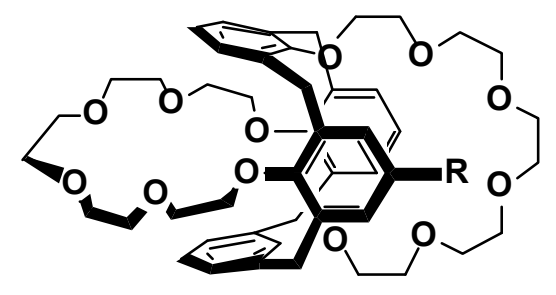


to allow adequate stripping. A related ionizable calixcrown in which a $-\mathrm{CH}_{3}$ group replaces the $-\mathrm{CF}_{3}$ group was synthesized and proved to be approximately three orders of magnitude easier to strip. These very promising results suggest that a cation-exchange principle may offer a highly effective alternative to neutral calixcrowns for cesium extraction.

\section{Planned Activities}

Several themes will be pursued in the second and third years of this project. New alkylated analogs to BOBCalixC6 will be characterized with regard to solubility and extraction behavior, and possibly two other candidates will be synthesized. Improved solubility is expected to offer significant improvement to the CSSX process in avoiding inadvertent crystallization of the extractant or third-phase formation. Future effort will also seek enhanced stripping by means of proton switches, that is, to use the large $\mathrm{pH}$ change from alkaline extraction conditions to weakly acidic stripping conditions to bring about dramatic decomplexation. In this connection, promising results on ionizable calixcrowns will be further pursued through collaboration with Prof. Bartsch at Texas Tech University. Both additional syntheses are proposed, together with characterization of their extraction behavior and equilibria. A collaboration has recently been initiated with Virginia Tech (Prof. H. W. Gibson) to improve our understanding of complexation of cesium and interactions with alkylamines. These studies are expected to provide insight into the role of the amine in CSSX, perhaps leading to more effective stripping methods. In general, equilibrium extraction and modeling studies will aim to elucidate thermodynamic processes of ion partitioning and complexation in systems containing selected calixcrowns, alcohol synergists, and alkylamines. Basic questions to resolve include the role of ion-pairing and dissociation, the solvation of the anion by the alcohol, the possible proton-ionizable nature of the alcohols, and the role of amine solvent components. Finally, it will be the goal to transfer this basic knowledge to collaborators, site users, private industry, and applied researchers associated with high-level waste remediation.

\section{Information Access}

See also www home page of the ORNL Chemical Separations Group: http://www.ornl.gov/csg. 